Western University

Scholarship@Western

Education Publications

Education Faculty

$7-2017$

Effects of Group Functional Behavior-Based Cognitive Behavioral Therapy for ObsessiveCompulsive Behavior in a Youth with Autism Spectrum Disorder

Nicole Neil

Western University,nneil@uwo.ca

Tricia Vause

Brock University

Heather Jaksic

Brock University

Maurice Feldman

Brock University

Follow this and additional works at: https://ir.lib.uwo.ca/edupub

Part of the Education Commons, and the Psychology Commons

Citation of this paper:

Neil, N., Vause, T., Jaksic, H., \& Feldman, M. (2017). Effects of group functional behavior-based cognitive-behavioral therapy for obsessive-compulsive behavior in a youth with Autism Spectrum Disorder, Child \& Family Behavior Therapy, 39(3), 179-190, doi: $10.1080 / 07317107.2017 .1338448$ 


\title{
Effects of Group Functional Behavior-Based Cognitive Behavioral Therapy for Obsessive- Compulsive Behavior in a Youth with Autism Spectrum Disorder
}

\author{
Nicole Neil, PhD, BCBA-D ${ }^{2}$, Tricia Vause, PhD, BCBA-D ${ }^{1,2}$, Heather Jaksic, MA, ${ }^{2}$, and \\ Maurice Feldman, $\mathrm{PhD}, \mathrm{BCBA}-\mathrm{D}^{1,2}$ \\ ${ }^{1}$ Department of Child and Youth Studies, Brock University, St. Catharines, Ontario, Canada \\ ${ }^{2}$ Centre for Applied Disability Studies, Brock University, St. Catharines, Ontario, Canada \\ Corresponding Author: \\ Tricia Vause, Ph.D., BCBA-D \\ Associate Professor \\ Department of Child and Youth Studies \\ and the Centre for Applied Disability Studies \\ Brock University \\ 1812 Sir Issaac Brock Way \\ St. Catharines, Ontario, Canada \\ L2S 3A1 \\ Ph: 905-688-5550, ext. 3559 \\ Fax: 905-641-2509 \\ Email: tvause@brocku.ca
}

Email addresses: Nicole Neil (nneil@ msu.edu); Tricia Vause (tvause@ brocku.ca); Heather Jaksic (hyates@brocku.ca); Maurice Feldman (mfeldman@brocku.ca)

\section{Acknowledgments}

This research was supported by the Ontario Mental Health Foundation and the Ministry of Health and Long-Term Care. Funding sources did not have a specific role in the study itself, or in decision to submit this paper for publication. 


\begin{abstract}
Individuals with Autism Spectrum Disorder (ASD) often present with comorbid Obsessive Compulsive Behaviors (OCBs), but little research exists on effective intervention for OCBs. Using a single-case experimental design, this study highlights the efficacy of a Group Functional Behavior-Based Cognitive-Behavior Therapy (Fb-CBT) to reduce OCBs in an 11year-old youth. Tailored for individuals with ASD, Fb-CBT included traditional CBT components (e.g., psychoeducation, cognitive-behavioral skills training, and exposure and response prevention), functional behavior assessment and intervention, and a group parenttraining component. Time-series parent report data and standardized OCB measures showed clinically significant decreases in OCBs, increase in psychosocial functioning, and high consumer satisfaction.
\end{abstract}

Keywords: obsessive compulsive disorder, autism, cognitive behavioral therapy, exposure and response prevention, functional assessment

\title{
Suggested citation:
}

Neil, N., Vause, T., Jaksic, H., \& Feldman, M. (2017). Effects of group functional behaviorbased cognitive-behavioral therapy for obsessive-compulsive behavior in a youth with Autism Spectrum Disorder, Child \& Family Behavior Therapy, 39(3), 179-190, doi:

$10.1080 / 07317107.2017 .1338448$ 


\section{Effects of Group Functional Behavior-based Cognitive Behavioral Therapy for Obsessive- \\ Compulsive Behavior in a Youth with Autism Spectrum Disorder}

A diagnostic requirement for Autism Spectrum Disorder (ASD) is restricted and/or repetitive behaviors (RRBs), including stereotyped movements, self-injury, need for sameness, compulsions, ritualized verbal and nonverbal behavior, and circumscribed or perseverative interests (DSM-5, American Psychiatric Association [APA], 2013). A subset of RRBs classified as "higher level" repetitive behavior (e.g., washing, rigid routines, ordering and arranging) may be similar to symptoms characteristic of Obsessive Compulsive Disorder (OCD; Mack et al. 2010). In fact, researchers provide preliminary support for compulsive, ritualistic and sameness behaviors loading on the same factor (Bishop et al., 2013; Mirenda et al., 2010). While these behaviors may be maintained by escape from anxiety, they may also serve other functions such as sensory stimulation or access to attention (Vause, Hoekstra, \& Feldman, 2014). Given difficulties in introspection and social-communicative challenges often experienced by individuals with ASD, determining the function can be difficult (Zandt, Prior, \& Kyrios, 2007). Recent studies report that $15 \%$ of individuals with ASD present with Obsessive Compulsive Behavior (OCB) and higher rates of anxiety are associated with lower quality of life (van Steensel, Bögels, \& Dirksen, 2012; van Steensel, Bögels, \& Perrin, 2011). Research is needed to develop evidence-based treatment for OCBs in ASD, including those controlled by escape from anxiety as well as other functions.

Cognitive-Behavior Therapy (CBT), including psychoeducation, cognitive training, mapping OCD, and exposure plus response prevention (ERP) is efficacious and recommended as first-line treatment for pediatric OCD (Watson \& Rees, 2008), but there is limited evidence with an ASD population. A series of case studies (e.g., Elliot \& Fitzsimons, 2014; Lehmkuhl, Storch, 
Bodfish, \& Geffken, 2008; Reaven \& Hepburn, 2003; Sze \& Wood, 2007; Vause et al., 2014) using adapted CBT (e.g., increased parent participation, protracted cognitive component, and ERP as the main ingredient) have shown decreases in OCBs in children and youth with highfunctioning ASD. For instance, based on the work of March and Mulle (1998), Vause et al. (2014) used a single-case experimental design to evaluate adapted CBT to treat contaminationrelated behaviors in two school-age children with ASD. As part of this treatment, functional behavior assessment and intervention was added to address perceived variables such as access to parental attention. Using time-series parent report data and standardized measures, the authors reported clinically significant decreases in OCBs, with maintained improvement at 3 to 4 month follow-up.

A series of small- $N$ experiments have also used behavior-analytic treatment to successfully reduce behaviors such as ordering and arranging (Leon, Lazarchick, Rooker, \& DeLeon, 2013; Rodriguez, Thompson, Schlichenmeyer, \& Stocco, 2012; Sigafoos, Green, Payne, \& O'Reilly, 2009), excessive straightening (Kuhn, Hardesty, \& Sweeney, 2009), and rigid routines (Rispoli, Camargo, Machalicek, Lang, \& Sigafoos, 2014) in children and youth with ASD and intellectual disabilities. Rodriguez et al. (2012) used an experimental functional analysis to determine the functions of arranging, ordering, completeness, and washing/cleaning behaviors in three adolescents (aged 13-15) with ASD. Functional analysis results suggested automatic (sensory) reinforcement as the maintaining variable for all three youth. Access to competing stimuli combined with response blocking and, in one case, product extinction (returning furniture to its original position) led to reductions of the target behaviors to near zero levels. In a review by Neil and Sturmey (2014), behavioral intervention met criteria for possibly efficacious treatment for OCB. 
A preliminary Randomized Controlled Trial (RCT; Vause, Neil, Jaksic, Jackiewicz, \& Feldman, 2015) tested the efficacy of a manualized treatment that combined CBT and functionalbased behavioral methodology to reduce OCBs in school-age children $(N=14)$ with high functioning ASD. Children who received a 9-week Functional Behavior-based CBT (Fb-CBT) package showed a significantly greater reduction in OCBs as compared to children in the Treatment as Usual (TAU) group, with medium to large effect sizes. In the current study, we present a single-case experimental design with time-series parent report data for an 11 year-old youth who participated in Fb-CBT as part of the RCT. In addition to demonstrating the efficacy of the Fb-CBT package, this case highlights the utility of intervention integrity for components of the intervention completed in the home and interobserver agreement for parent ratings of the frequency of compulsions.

\section{Method}

\section{Participant and Setting}

Ace (pseudonym) was an 11 year-old boy of divorced parents. His parents attended treatment on alternate weekends, with his mother and father attending four and five sessions, respectively. Ace did not receive any medication at entry nor for the duration of the study, and was not involved in other psychosocial interventions. He had a previous diagnosis of ASD (based on the DSM-IV-TR; APA, 2000) from a licensed psychologist that was confirmed by our Master's level psychometrist who was designated research reliable on the Autism Diagnostic Interview-Revised (ADI-R; Lord, Rutter, \& Couteur, 1994). Due to resource limitations, we were unable to administer the Autism Diagnostic Observation Scale (ADOS; Lord, Rutter, DiLavore, \& Risi, 1999). 
Using the Wechsler Intelligence Scale for Children-IV Short Form (WISC-IV Short Form; Weschler, 2004), his IQ was in the Borderline range. According to the Vineland-II (Sparrow, Cicchetti, \& Balla, 2005), Ace's communication and daily living skills were adequate and his socialization skills were moderately low. At entry, Ace and his mother reported the presence of OCBs; they endorsed items on the Sameness, Ritualistic and Compulsive subscales on the the Repetitive Behavior Scale-Revised (RBS-R; Bodfish, Symons, \& Lewis, 1999) and indicated meaningful impairment on the Child Obsessive-Compulsive Impact Scale-Revised (COIS-RP; Piacentini, Peris, Bergman, Chang, \& Jaffer, 2007).

\section{Measures}

The assessment battery was administered by an independent Master's level graduate student in Applied Disability Studies who was blind to the treatment assignment. The second author, Ph.D. in Clinical Psychology, provided over 70 hours of assessment training which included: co-rating videotaped and live interviews as well as conducting independent interviews/assessments and co-rating with at least 90\% reliability. Although both (divorced) parents participated in the intervention, Ace's mother served as the respondent on all assessment and treatment measures.

The Repetitive Behavior Scale-Revised (RBS-R). The RBS-R (Bodfish et al., 1999) is a rating scale for measuring the presence and severity of repetitive behaviors. Parents rate 43 items on a 4-point Likert-type scale ranging from (0) behavior does not occur, to (3) behavior occurs and is a severe problem. There are six conceptually derived subscales (Stereotyped Behavior, Self-injurious Behavior, Compulsive Behavior, Ritualistic Behavior, Sameness Behavior, and Restricted Behavior). Internal consistency for the subscales was equal or greater than .72 (Mirenda et al., 2010) with a three factor model comprised of: (a) self-injurious 
behavior; (b) restricted stereotypic behavior; and (c) compulsive, ritualistic and sameness behavior. For this participant, we examined the Sameness, Ritualistic, and Compulsive Subscales at pre, post, and 6 months post-treatment.

Children's Yale-Brown Obsessive-Compulsive Scale (CY-BOCS; Goodman, Price, Rasmussen, Riddle, \& Rapoport, 1986). The CY-BOCS is a 10-item, clinician-rated, semistructured interview used to assess symptom severity for individuals aged 6 to 17 years. The CYBOCS has high internal consistency and acceptable convergent and divergent validity (Scahill et al., 1997; Storch et al., 2004). The CY-BOCS was administered jointly to Ace and his mother. Given the RBS-R factor loading (Mirenda et al., 2010), symptom overlap on the RBS-R and CYBOCS, and the flexibility of the CY-BOCS in adding additional items that fit categories as 'other', items comprising the Sameness, Ritualistic, and Compulsive subscales (items 15 through 39) that were endorsed on the RBS-R were probed for inclusion on the CY-BOCS. For this study, the 5-item Compulsion score was reported pre- and post-treatment; due to parental time constraints, follow-up data was not collected.

The Child Obsessive-Compulsive Impact Scale-Revised (COIS-RP). The COIS-RP (Piacentini et al. 2007) is a 33-item, parent-report questionnaire that assesses OCD-related impairment in various areas of the child's life, including school, social, and home/family activities. For each item, the parent rated the child's level of impairment on a 4-point Likert scale from 0 (not at all) to 3 (very much). The COIS-RP has strong internal consistency and good testretest reliability (Piacentini et al., 2007).

Customer Satisfaction. At post-treatment, the parent rated how satisfied she was with the Fb-CBT intervention using on a 7-point Likert scale ranging between 1 (not at all satisfied) 
to 7 (very satisfied) using an adapted version of the Consumer Satisfaction Questionnaire (Feldman, Condillac, Tough, Hunt, \& Griffiths, 2002).

\section{Questions about Behavior Function (QABF) and Descriptive Functional Behavior}

Assessment. The QABF (Matson \& Vollmer, 1995) is a rating scale consisting of 25 items to address five behavior function domains: attention, escape, access to tangibles, physical discomfort, and nonsocial reinforcement. The items are rated on a 4-point Likert scale ranging from 0 (never) to 3 (often). It shows good psychometric properties for individuals with developmental disabilities, including ASD (Matson, Tureck, \& Rieske, 2012; Watkins \& Rapp, 2013). To supplement parent ratings, descriptive data was collected by therapists on the perceived antecedents and consequences of OCBs during home visits and in sessions (approximately 4 hours of observation for this participant).

Parent OCB Rating Scale. A Likert-type scale (Vause et al., 2015) ranging from 1 (desired post-treatment levels of OCBs) to 3 (partial improvement from pre-treatment levels) to 5 (pre-treatment levels of OCBs) was filled out by Ace's mother during baseline, intervention, and at 6,12 , and 20-month follow-up.

\section{Target Behaviors}

Ace's compulsions included ripping paper, sniffing paper, and counting his fingers in a specific order (see Table 1 for operational definitions). During treatment, Ace vocalized that if he did not engage in ripping and sniffing paper "something bad would happen." For counting fingers, Ace did not always vocalize numbers when he was counting his fingers; therefore, the operational definition captured only his finger movements. For this behavior, he did not identify an obsession but said that he "just had to." He reported that he did not want to engage in it, but 
could not stop the urge. He labelled counting fingers "ridiculous," and worried that others would find him "weird" because of his compulsion.

\section{Research Design}

This study received approval from the University Research Ethics board, and written informed assent and consent were obtained from Ace and his mother, respectively. We used a within-participant multiple baseline design across behaviors (Cooper, Heron, \& Heward, 2007) to investigate the effects of the Fb-CBT on parent report of Ace's compulsions. A baseline phase and three intervention phases were included in the design. The three intervention conditions in order were: (a) psychoeducation and mapping (PM), (b) individualized treatment of OCBs (functional behavior assessment and intervention, cognitive and behavioral skills training, ERP plus positive reinforcement); and (c) parent and child-led intervention. During PM, Ace's compulsions were treated collectively, as recommended in CBT manuals for pediatric OCD (e.g., March \& Mulle, 1998), but the two intervention phases involved implementation of individualized treatment plans for each OCB. The RBS-R and COIS-R were administered at pre, post-intervention and 6-month follow-up. CY-BOCS was administered at pre- and postintervention.

\section{Procedures}

Data Collection and Interobserver Agreement. Using information from standardized measures and parent/child input regarding the most problematic compulsions, we created operational definitions of each OCB and a parent rating data collection form. The primary therapist provided written definitions (e.g., "Today, did Ace have to sniff every sheet of paper or page in a book?") of Ace's behaviors to his mother and she completed daily ratings using a Likert scale ranging from 1 (e.g., "No, he didn't") to 5 (e.g., "Yes, he did") at the same time each 
day. For all behaviors, Likert scale items ranged from 1 (desired post-intervention levels of $O C B s$ ) to 5 (pre-intervention levels of OCBs). Ratings of " 3 " represented intermediary levels (e.g., "some of the pages/sheets").

Using a digital video camera, Ace's mother recorded sniffing and ripping paper, as these behaviors occurred primarily in the evening when they read a book together. Ace's mother was asked to record the entire duration of book reading three times per week. The primary therapist, naïve to the mother's rating of the sessions, used a random number generator to select days to record the compulsions, and coded them from the video recording using the same Likert scale as Ace's mother. One compulsion, counting fingers, was not rated by the primary therapist as the behavior occurred in multiple settings throughout the day and, therefore it was not possible for Ace's mother to complete video recordings. Interobserver agreement between the primary therapist and Ace's mother for the Likert ratings of each behavior was calculated for $38 \%$ of randomly selected recordings. Reliability was calculated as the number of agreements (on the rated score) divided by the number of agreements plus disagreements multiplied by $100 \%$ (Cooper et al., 2007). Mean reliability was $88 \%$ for ripping paper and $94 \%$ for sniffing paper.

Treatment Package. Building on the work of CBT researchers (e.g., March \& Mulle, 1998; Piacentini et al., 2007), the Fb-CBT include a manualized intervention protocol and accompanying children's workbook entitled "I Believe in Me Not OCB!" (Vause, Neil, Yates, \& Feldman, 2013a, b). Intervention involved nine weekly two-hour sessions, which included group activities, work in parent-child dyads, children's social activities, and group parent training. Ace was one of three children participating in a group with two therapists and one parent accompanying each child. Concepts and techniques were modified to meet the cognitive, linguistic, and social needs of children with high functioning ASD (See Table 2 for a description 
of treatment enhancements). The primary therapist (MA candidate in Applied Disability Studies with a specialization in Applied Behavior Analysis) and an assistant therapist (BA in Child and Youth Studies) administered the intervention. Therapist training consisted of reviewing the manual content, role-playing and feedback; therapists received at least two hours of weekly supervision from the second author to review session content and discuss individual program plans.

Phase 1: Psychoeducation and Mapping (PM). The initial sessions (Sessions 1 through the first half of Session 3) focused on introducing group expectations, rapport building, and introducing Ace to OCB as it related to his specific compulsions. When creating a concrete list of his obsessions and compulsions, Ace spoke in a quiet voice and indicated that he did not want other group members to hear him. He identified that he was angry for having to perform his compulsions yet he felt that he "just had to do them". Using concrete exercises, Ace was taught that OCB could be externalized, whereby he was the "boss" and with the assistance of his parents and other supporters, he could learn to control OCB. Further, he generated statements such as "Leave me alone!" and "I'll call the OCB police!" Ace used a fear thermometer to rate the severity of each behavior (i.e., how distressed he would be if he could not perform the compulsion), and then visually mapped his compulsions on one of three sections indicating: (a) complete control; (b) some control; (c) no control over performing the compulsion. This map was used as a tool for determining what order the compulsions would be targeted (i.e., least to most difficult) and allowed Ace to track his progress during intervention. Ace verbalized that he wanted to tackle ripping paper first because working on refraining from paper sniffing and counting would be more difficult. By the third session, Ace frequently volunteered to talk in front of the group (e.g., reviewing weekly homework from the workbook). 


\section{Phase 2: Individualized Treatment for OCBs Using Functional Behavior Assessment} and Cognitive and Behavioral Treatment Components.

Functional Behavior Assessment and Intervention. For each compulsion, the QABF (Matson \& Vollmer, 1995) was administered to a parent in order to determine perceived functions other than escape from anxiety. Analysis of antecedents and consequences and possible functions was conducted by researchers trained in applied behavior analysis using video recordings and live observations from sessions (approximately 4 hours of observation). Combining the QABF and descriptive assessments, perceived functions for all three of Ace's compulsions were non-social (sensory) reinforcement and access to attention.

Perceived functions were addressed with differential reinforcement of alternative and low rates of behaviors and extinction (Cooper et al., 2007). For each behavior, a written functional behavior assessment and intervention plan was provided that advised Ace's parent to minimize attention and redirect him (in a neutral voice) to use coping strategies and replacement behaviors that he was learning in therapy (e.g., squeezing his fists together, playing on the computer). His parents also were encouraged to provide positive attention for Ace's engagement in appropriate behavior.

Cognitive and Behavioral Strategies, ERP, and Positive Reinforcement. In Sessions 3 and 4, we begin individualized treatment for ripping paper and sniffing paper, respectively. Ace identified common triggers including the presence of books and pieces of paper. He appeared motivated to work on these behaviors, vocalizing that OCB was interfering with enjoying reading. Given observed limitations in recognizing and discussing obsessions, a protracted cognitive component included building on externalizing statements from PM (e.g., "Leave me alone!") to include positive self-statements referring to not engaging in ripping and sniffing (e.g., 
"I can do it. I'm not going to let OCB beat me!"). Ace was reviewed labelling his urge to rip and sniff paper as the presence of OCB and was taught to try actively ignoring it and "sit with the urge”, or engage in alternative behaviors such as squeezing his fists, hitting a pillow or an activity such as playing on the computer.

With the assistance of the therapist and parents, ERP involved creating a plan for exposure to his thoughts/urges and refraining from ripping and sniffing paper. As an example, the second response targeted was sniffing paper. For the first part of the week, his plan was to sniff only once per day, and then, for the last 3 days he planned to reduce sniffing paper to zero levels. He wrote these goals on a daily chart provided within the treatment workbook and at the end of each day he reported whether he met his goal to his mother who placed a checkmark on the chart. His mother was responsible for determining the accuracy of his self-report and preferred items (money) were provided when Ace reduced the frequency of compulsions to levels as set during intervention sessions. As the sessions progressed, he was observed by both the parent and therapist to be increasingly independent in generating and performing coping strategies. For decreasing sniffing, he built on strategies that he felt were successful for decreasing ripping. For example, when working on sniffing, therapists observed Ace performing Karate moves on his own, saying that he was "bossing back" OCB.

Beginning in Session 6, an individualized treatment plan was generated for counting fingers. Ace could not identify triggers for this behavior, which occurred across multiple situations. Ace's plan consisted of reducing the number of digits counted (11-12-13-18-19-20) to the last string of three (18-19-20), altering the order of digits counted, and reducing the daily episodes of counting. Ace vocalized that he was comfortable reducing the numbers in the chain from 6 numbers to a minimum of 3 numbers (while switching the ordering of numbers). 
Contingent on using his coping strategies and meeting his goals, Ace received parental verbal praise and a preferred tangible item on an intermittent schedule (i.e., his mother delivered praise for using his coping strategies on some, but not all, occasions).

Parent Training. Modules occurred while children were participating in social skills exercises (see Table 2) and eating snacks. Parent training included discussions of OCB etiology, maintenance, impact of stressors, perceived functions, key treatment components and relapse prevention. Therapists provided Ace's parents with hands-on behavioral skills training using modelling, role-playing, practice and feedback in implementing individualized cognitive strategies, response prevention and functional behavior-based reinforcement interventions. Parents received information on generalization of strategies to other behavior problems.

Phase 3: Parent and Child-Led Intervention. In this phase, for counting, Ace and his parents were instructed to continue practicing switching up the numbers 18-19-20 and reducing the episodes of counting. Throughout treatment and within this phase, Ace's mother reported that he was motivated to reduce this compulsion, and would independently refer to his workbook and written treatment plan. For sniffing and ripping, Ace continued to use the strategies successful for reducing these responses and maintaining the levels attained during intervention.

\section{Intervention Integrity}

Based on a treatment component checklist derived from the Vause et al. (2013a) manual, two trained observers viewed digital video of all nine sessions in a random order and completed treatment integrity (TI) checks. Agreement on intervention components completed was calculated by dividing the number of agreements by the number of agreements plus 
disagreements and multiplying by 100 (Cooper et al., 2007). Mean TI and TI interobserver agreement was $100 \%$.

The primary therapist also conducted TI checks on Ace and his mother's correct administration of the treatment components (e.g., use of replacement behaviors, parent implementation of intervention plan) in the home setting. TI checks were calculated for $100 \%$ of video recordings taken across all phases (23\% of ripping and sniffing data points). Mean TI was $84 \%$ (range $=74$ to $100 \%)$.

\section{Results}

Figure 1 shows the parent and therapist ratings of the frequency of Ace's compulsions across baseline, three treatment phases, and follow-up. Throughout baseline and PM (first treatment phase), Ace's home frequency ratings for all three target responses: ripping paper (baseline: $M=2.89$, PM: $M=2.78$ ), sniffing paper (baseline: $M=2.89$, PM: $M=3.0$ ), and counting fingers (baseline: $M=3.89$, PM: $M=4.63$ ). In Sessions 3 and 4, when individualized treatment was introduced for ripping and sniffing paper, there was a decrease in frequency ratings for ripping paper $(M=1.2)$ and sniffing paper $(M=1.15)$ relative to baseline and PM, which remained low throughout intevention and zero levels at follow-up.

Counting fingers did not decrease during the first two treatment phases (PM and individualized treatment), but reduced to zero levels during parent and child-led intervention. At 6, 12, and 20-month follow-up, Ace's mother rated all three compulsions as 1, or not occuring. Consequently, all three OCBs were effectively diminished with our multi-component treatment plan.

Results of RBS-R, CY-BOCS and Secondary Outcome Measures. At post-test, the Sameness, Ritualistic and Compulsive Scales of the RBS-R showed a decrease in OCB severity 
from 15 to 5 and a reduction to 3 at 6-month follow-up. Lower scores on the RBS-R indicate lower interference and severity of the repetitive behavior (maximum score $=75$ ). Ace's pre to post CY-BOCS compulsion score decreased from 12 to 8 , with lower scores indicating lower severity of compulsions (maximum score $=20$ ). From pre to post-intervention, the COIS-R showed a decrease in OCD-related impairment from 59 to 5, and a reduction to 0 at 6- month follow-up. As a lower score (maximum score $=99$ ) on the COIS-R indicates less familial disruption related to the participant's problem behavior(s), these results reveal substantial improvements. The consumer satisfaction questionnaire revealed a high level of satisfaction with treatment indicated by a score of 7 out of 7 .

\section{Discussion}

There is growing evidence for adapted CBT as an efficacious treatment for addressing OCBs in children and youth with ASD (Reaven \& Hepburn, 2003; Vause et al., 2015). In the present study, a nine-session Fb-CBT treatment followed by parent and child-led intervention resulted in parent ratings of OCBs reducing to zero levels with maintained improvement at 20month follow-up. Standardized measures complemented these findings with considerable decreases in symptom severity and an increase in psychosocial functioning. In addition, Ace's mother reported high consumer satisfaction with the treatment package. These results are consistent with intervention literature on repetitive behavior in individuals with other developmental disabilities suggesting that involving key individuals such as parents, not only results in high social validity, but also helps maintain the positive results of treatment (Patterson, Smith, \& Jelen, 2010). In addition to demonstrating the efficacy of the Fb-CBT package, intervention integrity for components of the intervention completed in the home and interobserver agreement for parent ratings of the frequency of compulsions were high. 
Results of the study give some indication to the active ingredients of the intervention package, although component analysis is needed to further confirm these results. During psychoeducation and mapping, Ace's OCBs remained similar to baseline levels. It was not until the individualized treatment plans were introduced that parent ratings of OCB decreased. These results are consistent with previous studies (Vause et al., 2014; 2015) which noted that ratings of OCBs only decreased when individualized treatment consisting of functional behavior-based intervention, cognitive and behavioral skills training, ERP plus positive reinforcement was introduced. This suggests that the PM components of intervention, alone, are not sufficient to produce changes in OCBs. It is unclear, however, whether these components are necessary tofacilitate the efficacy of the subsequent individualized intervention plans. For example, Ace continued to spontaneously use statements to "boss back" OCB throughout intervention sessions and on video-recordings taken in the home; thus, there likely was carry-over of PM components into the individualized treatment phases.

For counting fingers, response to intervention only occurred when parent and child-led intervention was introduced. During this phase, the family was no longer attending sessions at the center, but was encouraged to continue to use the techniques and workbook provided during the course of intervention. There are several reasons as to why this OCB may have had a delayed treatment response. In comparison to the other two behaviors, counting fingers took place across multiple settings and was sometimes covert. During intervention, this may have presented some challenges regarding parents' ability to coach Ace when he performed the response alone or when they did not see the response occurring. This behavior was also rated by Ace and his mother as the most severe behavior during baseline assessment and Ace reiterated this fact throughout intervention. Future studies may explore which OCB topographies are more or less 
responsive to $\mathrm{Fb}$-CBT approaches to intervention and possible enhancements for OCBs of greater severity.

Consistent with previous case examples of interventions for OCB in individuals with ASD (Elliot \& Fitzsimons, 2014; Lehmkuhl et al., 2008; Nadeau Arnold, Selles, Storch, \& Lewin, 2014; Reaven \& Hepburn, 2003), we included modifications including visuals, selfmonitoring, and functional behavior-based intervention components (Iovannone, Dunlap, Huber, \& Kincaid, 2003). Future research involving OCB and ASD should continue to evaluate the benefits of including functional behavior assessment and intervention. In this study, the use of an indirect functional behavioral assessment identified perceived functions (e.g., attention) in addition to anxiety reduction of Ace's compulsions. There is growing evidence that functional assessment may be effective at identifying the functions of responses topographically similar to compulsions (e.g., arranging objects) and that interventions based on the results of these assessments are effective in reducing the frequency of these responses (Kuhn et al., 2009; Rodriguez et al., 2012).

In this study, reliability between Ace's mother's ratings of his behavior and the therapist observations coded from video recordings were high. For the discrepancies that did occur, Ace's mother reported the behavior occurring, while the therapist did not. This could be due to sampling; for example, it is possible that not all reading episodes during an entire day were captured on video recording. Ace's mother recorded his book reading during the evening, which was the primary time when this behavior occurred. It is possible that this behavior may have occurred during the day, which was not captured on video recordings. For some behaviors such as counting fingers, it was not possible to obtain a sample equivalent to what the Ace's mother rated. Where possible, researchers should simultaneously collect parent and experimenter ratings 
of the same behavior to determine inter-observer reliability. In doing so, researchers need to be aware of additional complexities such as their covertness or a child's hesitancy to perform the behavior in the presence of others.

In the home setting, Ace's mother delivered the treatment components (e.g., use of replacement behaviors, parent implementation of reinforcement contingencies) with high levels of integrity. Ace was observed to use the coping statements such as "Buzz off," "Go away," and "Stop" in the home. He also displayed trained alternative responses including hitting a pillow and squeezing his hands. Lapses in integrity were the result of Ace's mother providing reprimands for Ace engaging in the behavior in addition to, and in some instances, in place of redirecting and providing praise for Ace using his coping strategies. Throughout intervention, Ace appeared motivated to decrease his compulsions which likely contributed to independent performance of his coping statements and alternative behaviors in the absence of his mother's direction.

This study has some limitations. First, results are limited in their generalizability. Also, due to resource limitations, we were unable to administer the Autism Diagnostic Observation Scale (ADOS; Lord, Rutter, DiLavore, \& Risi, 1999) to complete our own diagnostic assessment of ASD. We did not observe Ace's behavior at his father's residence and standardized assessments were not completed by Ace's father as Ace primarily resided with his mother. However, Ace's father stated that he observed improvement in Ace's behavior over sessions and was impressed with the success of the treatment. Third, the CY-BOCS was only completed pre and post-treatment and not in follow-up due to parental time constraints. Last, we were not able to obtain an equivalent sample of video-recordings for counting fingers given that this behavior occurred in multiple settings throughout the day. 
Using a single-case experimental design, this study highlights the promising results of one participant who took part in a preliminary RCT that explored an adapted functional behavior-based CBT treatment. Observations revealed high agreement in ratings of OCB severity between the primary therapist and Ace's mother, and high integrity of intervention components completed in the home. Future studies should continue to assess, when possible, both reliability and intervention integrity outside of intervention. 


\section{References}

American Psychiatric Association (2013). Diagnostic and statistical manual of mental disorders (5th ed.). Washington, DC: American Psychiatric Association.

American Psychiatric Association. (2000). Diagnostic and statistical manual of mental disorders. (4th Rev. ed.). Washington, DC: American Psychiatric Association.

Bishop, S. L., Hus, V., Duncan, A., Huerta, M., Gotham, K., Pickles, A.,... Lord, C. (2013) Subcategories of restricted and repetitive behaviors in children with autism spectrum disorders. Journal of Autism and Developmental Disorders, 43, 1287-1297. doi:10.1007/s10803-012-1671-0

Bodfish, J. W., Symons, F. J., \& Lewis, M. H. (1999). The Repetitive Behavior Scale: Test Manual. Morganton: Western Carolina Center Research Reports.

Cooper, J. O., Heron, T. E., \& Heward, W. L. (2007). Applied Behavior Analysis (2nd ed.). New Jersey, NY: Pearson Education Inc.

Elliott, S. J., \& Fitzsimons, L. (2014). Modified CBT for treatment of OCD in a 7-year-old boy with ASD: A case report. Journal of Child and Adolescent Psychiatric Nursing, 27(3), 156-159. doi: 10.1111/jcap.12081

Feldman, M. A., Condillac, R. A., Tough, S., Hunt, S., \& Griffiths, D. (2002). Effectiveness of community positive behavioral intervention for persons with developmental disabilities and severe behavior disorders. Behavior Therapy, 33(3), 377-398. doi:10.1016/S00057894(02)80034-X

Goodman, W. K., Price, L. H., Rasmussen, S. A., Riddle, M. A. \& Rapoport, J. L. (1986). Children's Yale-Brown Obsessive Compulsive Scale (CY-BOCS). National Institutes of Mental Health (public domain). 
Iovannone, R., Dunlap, G., Huber, H., \& Kincaid, D. (2003). Effective educational practices or students with autism spectrum disorders. Focus on Autism and Other Developmental Disabilities, 18(3), 150-165. doi:10.1177/10883576030180030301.

Kuhn, D. E., Hardesty, S. L., \& Sweeney, N. M. (2009). Assessment and treatment of excessive straightening and destructive behavior in an adolescent diagnosed with autism. Journal of Applied Behavior Analysis, 42(2), 355-360. doi:10.1901/jaba.2009.42-355

Lehmkuhl, H. D., Storch, E. A., Bodfish, J. W., \& Geffken, G. R. (2008). Brief report: Exposure and response prevention for obsessive compulsive disorder in a 12-year-old with autism. Journal of Autism and Developmental Disorders, 38(5), 977-981. doi:10.1007/s10803007-0457-2

Leon, Y., Lazarchick, W. N., Rooker, G. W., \& DeLeon, I. G. (2013). Assessment of problem behavior evoked by disruption of ritualistic toy arrangements in a child with autism. Journal of Applied Behavior Analysis, 46(2), 507-511. doi:10.1002/jaba.41

Lord, C., Rutter, M., \& Couteur, A. L. (1994). Autism diagnostic interview-revised: A revised version of a diagnostic interview for caregivers of individuals with possible pervasive developmental disorders. Journal of Autism and Developmental Disorders, 24(5), 659685. doi:10.1007/BF02172145

Lord, C., Rutter, M., DiLavore, P. C., \& Risi, S. (1999). Autism diagnostic observation schedule. Los Angeles, CA: Western Psychological Services.

Mack, H., Fullana, M. A., Russell, A. J., Mataix-Cols, D., Nakatani, E., \& Heyman, I. (2010). Obsessions and compulsions in children with asperger's syndrome or high-functioning autism: A case-control study. Australian and New Zealand Journal of Psychiatry, 44(12), 1082-1088. doi: 10.3109/00048674.2010.515561 
March, J. S., \& Mulle, K. (1998). OCD in Children and Adolescents: A Cognitive-Behavioral Treatment Manual. New York, NY: The Guilford Press.

Matson, J. L., Tureck, K., \& Rieske, R. (2012). The Questions About Behavioral Function (QABF): Current status as a method of functional assessment. Research in Developmental Disabilities, 33(2), 630-634. doi:10.1016/j.ridd.2011.11.006

Matson, J. L, \& Vollmer, T. R. (1995). User's Guide: Questions About Behavioral Function $(Q A B F)$. Baton Rouge, LA: Scientific Publishers, Inc.

Mirenda, P., Smith, I. M., Vaillancourt, T., Georgiades, S., Duku, E., Szatmari, P., ... Zwaigenbaum, L. (2010). Validating the repetitive behavior scale- revised in young children with autism spectrum disorder. Journal of Autism and Developmental Disorders, 40(12), 1521-1530. doi:10.1007/s10803-010-1012-0

Nadeau, J. M., Arnold, E. B., Selles, R. R., Storch, E. A., \& Lewin, A. B. (2014). A Cognitivebehavioral approach for anxiety in a preschool-aged child with Autism Spectrum Disorder. Clinical Case Studies, 14, 47-60. doi: 10.1177/1534650114536028.

Neil, N., \& Sturmey, P. (2014). Assessment and treatment of obsessions and compulsions in individuals with autism spectrum disorders: A systematic review. Review Journal of Autism and Developmental Disorders, 1(1), 62-79. doi:10.1007/s40489-013-0006-1

Patterson, S. Y., Smith, V., \& Jelen, M. (2010). Behavioural intervention practices for stereotypic and repetitive behaviour in individuals with autism spectrum disorder: A systematic review. Developmental Medicine and Child Neurology, 52(4), 318-327. doi: 10.1111/j.1469-8749.2009.03597.x

Piacentini, J., Peris, T. S., Bergman, R. L., Chang, S., \& Jaffer, M. (2007). Brief report: functional impairment in childhood OCD: Development and psychometrics properties of 
the child obsessive-compulsive impact scale-revised (COIS-R). Journal of Clinical Child and Adolescent Psychology, 36(4), 645-653. doi: 10.1080/15374410701662790

Reaven, J., \& Hepburn, S. (2003). Cognitive-behavioral treatment of obsessive-compulsive disorder in a child with asperger syndrome: A case report. Autism, 7(2), 145-164. doi:10.1177/1362361303007002003

Rispoli, M., Camargo, S., Machalicek, W., Lang, R., \& Sigafoos, J. (2014). Functional communication training in the treatment of problem behavior maintained by access to rituals. Journal of Applied Behavior Analysis, 47(3), 580-593. doi: 10.1002/jaba.130

Rodriguez, N. M., Thompson, R. H., Schlichenmeyer, K., \& Stocco, C. S. (2012). Functional analysis and treatment of arranging and ordering by individuals with an autism spectrum disorder. Journal of Applied Behavior Analysis, 45(1), 1-22. doi:10.1901/jaba.2012.45-1

Scahill, L., Riddle, M. A., McSwiggin-Hardin, M., Ort, S. I., King, R. A., Goodman, W. K.,... Leckman, J. F. (1997). Children's yale-brown obsessive-compulsive scale: Reliability and validity. Journal of the American Academy of Child and Adolescent Psychiatry, 36(6), 844-852. doi:10.1097/00004583-199706000-00023

Sigafoos, J., Green, V. A., Payne, D., O’Reilly, M. F., \& Lancioni, G. E. (2009). A classroombased antecedent intervention reduces obsessive-repetitive behavior in an adolescent with autism. Clinical Case Studies, 8(1), 3-13. doi:10.1177/1534650108327475

Sparrow, S. S., Cicchetti, D. V., \& Balla, D. A. (2005). Vineland II: A Revision of the Vineland Adaptive Behavior scales: I. Survey/Caregiver Form (2nd edn). Circle Pines, Minnesota: American Guidance Service 
Storch, E. A., Murphy, T. K., Geffken, G. R., Soto, O., Sajid, M., Allen, P.,... Goodman, W. K. (2004). Psychometric evaluation of the children's yale-brown obsessive-compulsive scale. Psychiatry Research, 129(1), 91-98. doi:10.1016/j.psychres.2004.06.009

Sze, K. M., \& Wood, J. J. (2007). Cognitive behavioral treatment of comorbid anxiety disorders and social difficulties in children with high-functioning autism: A case report. Journal of Contemporary Psychotherapy, 37(3), 133-143. doi:10.1007/s10879-007-9048-y

van Steensel, F. J., Bögels, S. M., \& Dirksen, C. D. (2012). Anxiety and quality of life: Clinically anxious children with and without autism spectrum disorders compared. Journal of Clinical Child \& Adolescent Psychology, 41(6), 731-738. doi: $10.1080 / 15374416.2012 .698725$

van Steensel, F. J., Bögels, S. M., \& Perrin, S. (2011). Anxiety disorders in children and adolescents with autistic spectrum disorders: A meta-analysis. Clinical Child and Family Psychology Review, 14(3), 302-317. doi:10.1007/s10567-011-0097-0

Vause, T., Hoekstra, S., \& Feldman, M. (2014). Evaluation of individual function-based cognitive-behavioural therapy for obsessive compulsive behaviour in children with autism spectrum disorder. Journal on Developmental Disabilities, 20(3), 30-41.

Vause, T., Neil, N., Yates, H., \& Feldman, M. (2013a). I Believe in Me Not OCB!: Clinician's Manual. Unpublished manuscript, Brock University, St. Catharines, ON.

Vause, T., Neil, N., Yates, H., \& Feldman, M. (2013b). I Believe in Me Not OCB!: Workbook. Unpublished manuscript, Brock University, St. Catharines, ON.

Vause, T., Neil, N., Jaksic, H., Jackiewicz, G., \& Feldman, M. (2015). Preliminary randomized trial of function-based cognitive-behavioral therapy to treat obsessive compulsive 
behavior in children with autism spectrum disorder. Focus on Autism and Other Developmental Disabilities, 1-11. doi: 10.1177/1088357615588517.

Watkins, N., \& Rapp, J. T. (2013). The convergent validity of the Questions About Behavioral Function scale and functional analysis for problem behavior displayed by individuals with autism spectrum disorder. Research in Developmental Disabilities, 34(1), 11-16. doi:10.1016/j.ridd.2012.08.003

Watson, H. J., \& Rees, C. S. (2008). Meta-analysis of randomized, controlled treatment trials for pediatric obsessive-compulsive disorder. Journal of Child Psychology and Psychiatry, 49(5), 489-498. doi:10.1111/j.1469-7610.2007.01875.x

Wechsler, D. (2004). Wechsler Intelligence Scale for Children - Fourth Edition (WISC-IV). San Antonio: TX: The Psychological Corporation.

Zandt, F., Prior, M., \& Kyrios, M. (2007). Repetitive behavior in children with high functioning autism and obsessive compulsive disorder. Journal of Autism and Developmental Disorders, 37, 251-259. doi: 10.1007/s10803-006-0158-2 
Table 1

Operational Definitions for Ace's Target Responses.

Behavior

Operational Definition

Sniffing Sniffing paper occurred when Ace brought a book or piece of paper to his nose

Paper and inhaled

Ripping Ripping paper occurred when Ace placed a small tear in the upper right hand Paper corner of a piece of paper or book

Counting Counting fingers occurred when Ace curled his two pointer fingers inward and fingers moved them back and forth in rapid succession. This was or was not accompanied by the vocalization "11-12-13-18-19-20." 
Table 2

Treatment Modifications for Individuals with ASD

\begin{tabular}{ll}
\hline Modification & Description \\
\hline Repetitiveness/ & Provided structure and predictability by following a \\
Predictability of & predetermined program plan. Treatment components (e.g., \\
Treatment & group work, individual parent-child dyads) were in the same \\
& order each week. Weekly session schedules were presented in \\
& the workbook and on a whiteboard. Although predictable, we \\
& gradually encouraged work on flexibility through introducing \\
& new behaviors with individualized adaptations (e.g., use of \\
& visuals, type of cognitive training) and schedules were adjusted \\
& (e.g., an activity out of sequence).
\end{tabular}

Emphasis on visuals, Workbook contained visuals (in addition to text) to illustrate choice of response modality, and concrete exercises concepts, and child activities included choice in drawing, writing, and/or responding vocally. Activities were tangible (e.g., tracking progress in resisting compulsions with clear visual markers such as numbers).

Within Session Rules and Token System

Session rules pertaining to social-communicative and on-task behavior were reviewed weekly and practiced during individual and group activities. Children earned ten tokens for following session rules and exchanged them for a back-up reinforcer (e.g., preferred tangible) at the end of session.

Immediate and Delayed Preferred items were delivered for completing ERP goals. Reinforcers Items were written in the workbook and earned if the child accomplished his/her goals daily and response requirements were gradually increased.

Incorporation of Child's Children's unique interests were incorporated into the therapy Interests components (e.g., using stickers with their favorite character) or including a favorite character as part of their support team.

Social Skills Exercises Social skills activities (with and without parents) are incorporated into each session. Social skill components became progressively more difficult (and build on skills learned in previous sessions). 


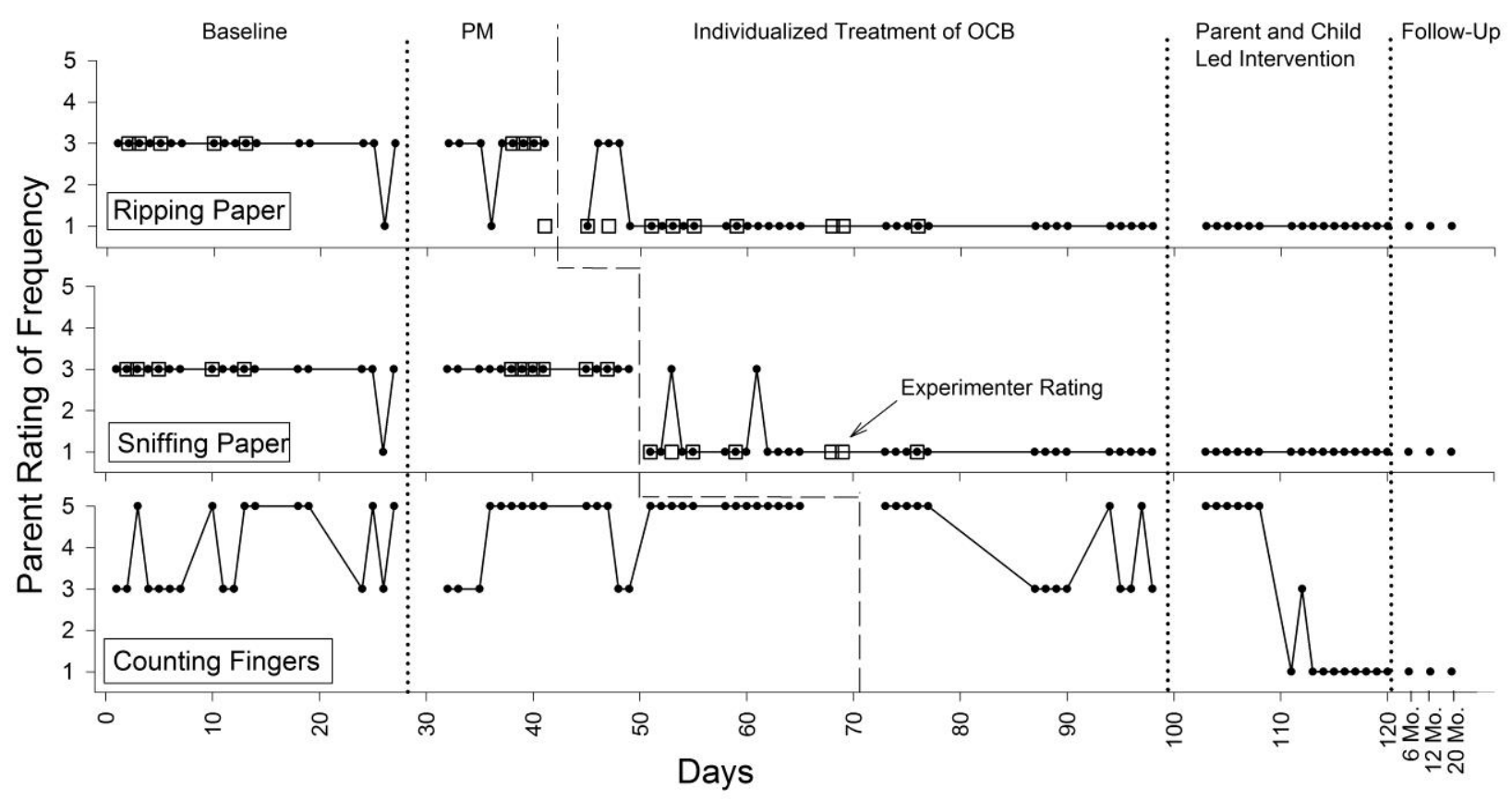

Figure 1. Parent (closed circles) and experimenter (open squares) ratings of the frequency of compulsions during baseline, psychoeducation and mapping (PM), individualized treatment of OCB, parent- and child-led intervention, and at 6,12, and 20 month follow-up. 